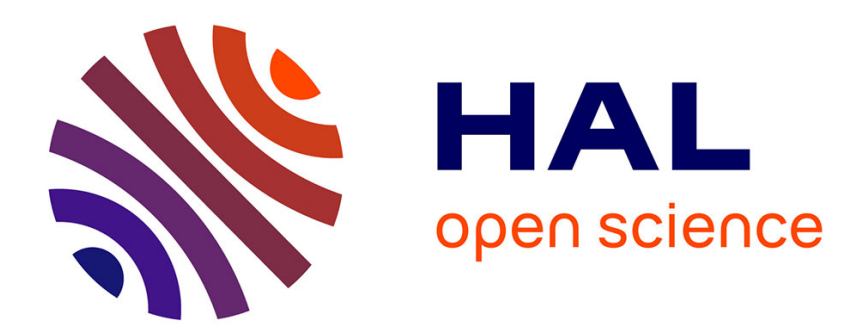

\title{
Cryo-MOSFET and IGBT : a Comparison
}

O. Mueller

\section{- To cite this version:}

O. Mueller. Cryo-MOSFET and IGBT: a Comparison. Journal de Physique IV Proceedings, 1996, 06 (C3), pp.C3-219-C3-224. 10.1051/jp4:1996333 . jpa-00254251

\section{HAL Id: jpa-00254251 https://hal.science/jpa-00254251}

Submitted on 1 Jan 1996

HAL is a multi-disciplinary open access archive for the deposit and dissemination of scientific research documents, whether they are published or not. The documents may come from teaching and research institutions in France or abroad, or from public or private research centers.
L'archive ouverte pluridisciplinaire HAL, est destinée au dépôt et à la diffusion de documents scientifiques de niveau recherche, publiés ou non, émanant des établissements d'enseignement et de recherche français ou étrangers, des laboratoires publics ou privés. 


\title{
Cryo-MOSFET and IGBT: a Comparison
}

\author{
O. Mueller
}

American Superconductor Corporation, 2 Technology Drive, Westborough, MA 01581, U.S.A.

\begin{abstract}
The preferred device for power eletronics in the multi-kilowatt / $300-1000 \mathrm{~V}$ range is today the IGBT (Insulated Gate Bipolar Transistor). It may in the near future see an emerging strong competitor for certain suitable applications: The Cryo-MOSFET. This paper compares the main properties of these two devices. It demonstrates that the Cryo-MOSFET in combination with high-temperature superconductors (HTS) can do to the field of power electronics what integrated circuit (IC) technology has done to the computer and communication industry: The ultimate in size, weight and cost reduction.

The Cryo-MOS technology is based on the fact that the on-resistance of high-voltage devices decreases dramatically at cryogenic temperatures. This is due to the majority carrier mobility increase in the drain-source drift region. The on-state conduction losses in high-power switch-mode circuits can then be made as small as desirable by paralleling, because MOSFETs as ohmic devices do not exhibit an on-state threshold voltage as the IGBT, the MCT, the GTO, etc.
\end{abstract}

\section{THE CRYO-MOSFET}

The invention of high-temperature superconductors (HTS) invites circuit designers to investigate the feasibility of combining them with low temperature operated signal and power electronics [1-5]. A suitable active device is the Cryo-MOSFET, or in short the Cryo-MOS. It is defined as any 'standard' or 'avalanche rated' [6] metal-oxide-silicon field-effect power transistor which operates, i.e. can be turned on and off, if immersed in liquid nitrogen (LN2) at a temperature of $\mathrm{T}=77 \mathrm{~K}$. Not all MOSFETs are suitable as Cryo-MOS. So-called FREDFETs (Siemens) or HYPERFETs (IXYS) do not work at cryogenic temperatures.

The main advantage of the Cryo-MOS is that its on-resistance, $\mathrm{R}$ (on), drops at $77 \mathrm{~K}$ by a factor $\mathrm{F}=10-15$ $>4$ compared to the room temperature $(\mathrm{T}=300 \mathrm{~K})$ value [3]. $\mathrm{F}$ depends on the breakdown voltage. Another key advantage is the zero on-state threshold voltage which permits conduction loss reduction to any desired low level by paralleling more devices. ("Silicon is cheap!") This feature is not provided by IGBTs and other power devices such as GTOs, MCTs etc. as shown by Figure 1 where the low-voltage output current/voltage characteristics of several components are plotted.

On-Resistance, 500 V MOSFET. Experimental Results: The measured on-resistance of a $600 \mathrm{~V}, 23$ A, $0.3 \Omega$ power MOSFET APT6030BN (TO-247 plastic package) is shown in Figure 2. The room temperature measurement was carried out with the MOSFET screw-mounted on an aluminum heatsink with a circa 2 second DC pulse. At $77 \mathrm{~K}$ the device was just immersed into liquid nitrogen without a heatsink. One can see that the improvement factor $\mathrm{F}$ at a low drain current is almost $\mathrm{F}=10$ and increases rapidly. The corresponding conduction loss as a function of the drain current is plotted in Figure $\mathbf{3}$ for $\mathrm{T}=300 \mathrm{~K}$ and $\mathrm{T}=77 \mathrm{~K}$. The first $500 \mathrm{~V}, 50 \mathrm{~A}$ MOSFET in a low-cost TO-264 (TO-3PL) package, the 2SK1837 from Hitachi, behaved somewhat differently. Its on-resistance at $77 \mathrm{~K}$ decreases with increasing drain current, Figure 4. This may be due to a partial carrier freeze-out which disappears with increasing junction temperature.

On-Resistance, $1000 \mathrm{~V}$ MOSFET: Figures 5 and 6 show the $77 \mathrm{~K}$ on-resistance versus drain current curves for a Motorola and IXYS $1000 \mathrm{~V}, 14 \mathrm{~A}$ MOSFET with differing thermal resistance of $0.42 \mathrm{~K} / \mathrm{W}$ and $0.35 \mathrm{~K} / \mathrm{W}$ respectively. A new 'avalanche rated' [6] MOSFET APT10053LNR (1000 V, $20 \mathrm{~A}, 0.53$ $\Omega, 0.24 \mathrm{~K} / \mathrm{W}$ ) in the new TO-264 package has also been investigated. Figure 7 shows the drain current, drain-source voltage characteristics for the room temperature operation $(300 \mathrm{~K})$ and the cooled condition 


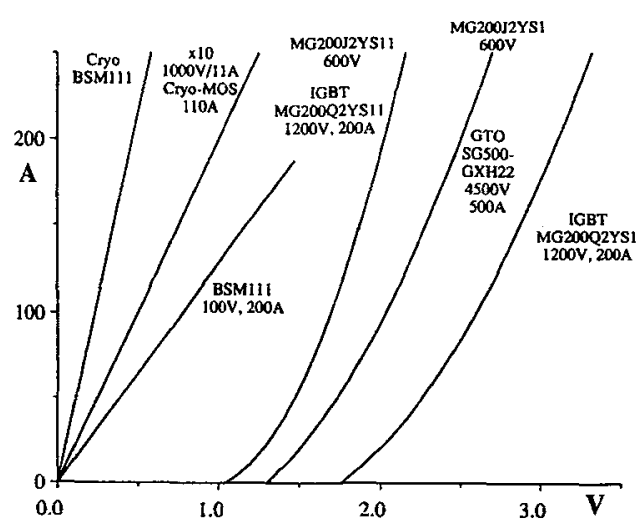

Typical On-State Voltages: IGBT, GT0, MOS

Figure 1

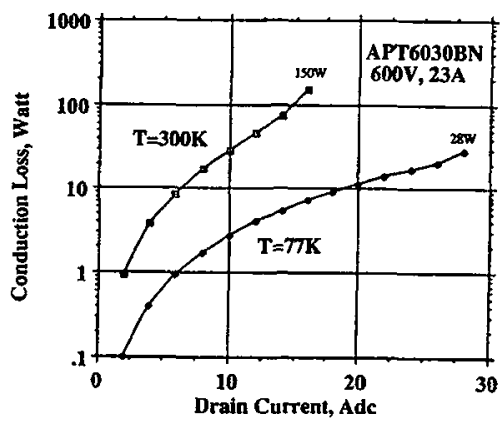

APT6030BN, Conduction Loss versus Drain Current

Figure 3

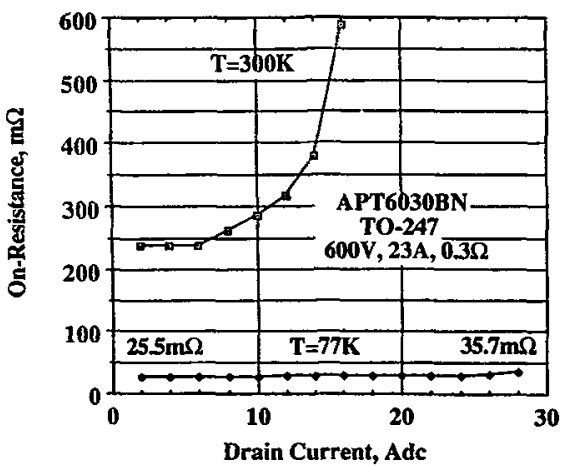

APT6030BN, On-Resistance vs Drain Current

Figure 2

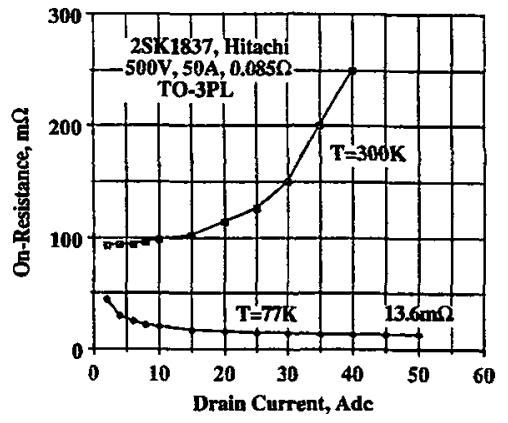

2SK1837, On-Resistance vs Drain Current

Figure 4

On-Resistance, MTY14N100E, $77 \mathrm{~K}$

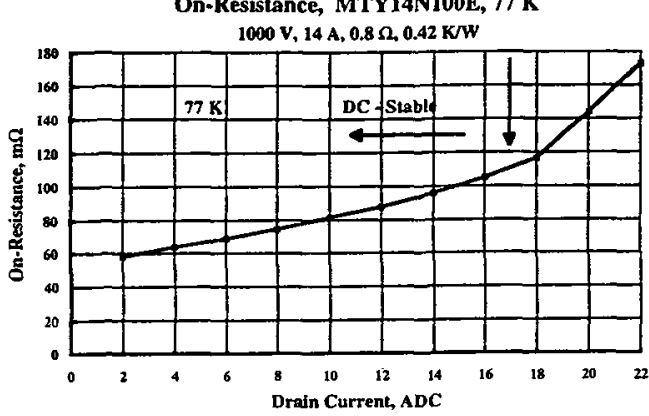

Figure 5

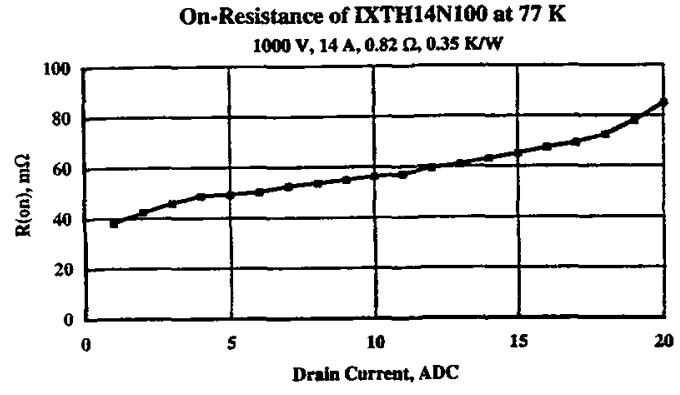

Figure 6 
$(77 \mathrm{~K})$. The area between the two curves represents the gain obtained by the cryo-cooling. In Figure 8 the measured on-resistance at $77 \mathrm{~K}$ is plotted as a function of drain current for two cases. The first curve was obtained with the TO-264 package just immersed in liquid nitrogen (LN2). Here, DC stable operation was obtained up to a drain current of $28 \mathrm{~A}$. The power dissipation, at this current, is about $33 \mathrm{~W}$. The maximum heat flux which nucleate boiling of $\mathrm{LN} 2$ can accomodate is around $12 \mathrm{~W} / \mathrm{cm}^{2}[7]$. The heatsinking metal area of the TO-264 package is about $4 \mathrm{~cm}^{2}$. This corresponds to a power dissipation of $\mathrm{P}=$ $4 \mathrm{~cm}^{2} \times 12 \mathrm{~W} / \mathrm{cm}^{2}=48 \mathrm{~W}$. One can see that approximately at this power level thermal run-away occurs (Figure 8). With the MOSFET soldered (with indium solder) on a copper heatsink one gets DC stable (!) operation up to a drain current of $60 \mathrm{~A}(!)$ in a $20 \mathrm{~A}$ rated device. This is a factor of 3 increase corresponding to a factor of 9 higher power handling capability. The dissipation is here $\sim 300 \mathrm{~W}$. An interesting feature is that at room temperature the on-state voltage is never stable at higher currents due to the internal junction temperature increase whereas it is DC stable at $77 \mathrm{~K}$ up to a certain current depending on the thermal resistance. (The on-resistance measurements are made with a power supply in the constantcurrent mode of operation). These facts are illustrated by the measurements of Figure 9. The onresistance or on-state voltage of the APT10053LNR indium soldered on a copper heatsink at $50 \mathrm{~A}$ are rock-stable with time at $77 \mathrm{~K}$ whereas they both increase drastically within minutes at $300 \mathrm{~K}$ for a current of only $5 \mathrm{~A}$, an amazing feature of the Cryo-MOS.

Figure 10 presents the on-resistance curve for the largest MOSFET chip available today in the ISOTOP package: APT10026JN, $1000 \mathrm{~V}, 33 \mathrm{~A}, 0.26 \Omega, 0.18 \mathrm{~K} / \mathrm{W}$. With the device immersed in LN2 (no heatsink) the on-state voltage (and on-resistance) are DC-stable up to a drain current of $55 \mathrm{~A}$. The measurements from $55 \mathrm{~A}$ up to $100 \mathrm{~A}$ correspond to a 2 second DC pulse. They were all made with a standard gate-source voltage of $15 \mathrm{VDC}$. The low-current improvement factor $F$ for this $1000 \mathrm{~V}$ device is $\mathrm{F}=220 / 16=13.75$ and it increases to infinity. In Figure 11 the on-resistance dependence as a function of V(GS) is given for two APT10053LNR chips (dies) mounted in parallel. Figure 12 shows how, by third quadrant operation, the Cryo-MOS can be used as an ideal synchronous rectifier over a much larger current range than at room temperature.

Temperature Dependence of the On-Resistance: Figures 13 and 14 show the measured R(on) temperature dependence of a APT10053LNR (heatsink mounted) on a linear and logarithmic scale. Internal heating for a drain current of $1 \mathrm{~A}$ is neglegible due to the low thermal resistance of the device: $0.24 \mathrm{~K} / \mathrm{W}$. Therefore this curve can be used as a temperature scale. This means the temperature difference for a given $\mathrm{R}(\mathrm{on})$ between the $1 \mathrm{~A}$ curve and another higher current curve gives the junction temperature rise. Optimization of Cryo-MOSFET design has been investigated by Singh/Baliga [10].

Thermal Resistance: If one compares the decreasing slope of the curves of Figures 5,6 and 8 in the 5 20 A range one can clearly see a relationship with the decreasing thermal resistance of these 3 MOSFETs from $0.42 \mathrm{~K} / \mathrm{W}, 0.35 \mathrm{~K} / \mathrm{W}$ to $0.24 \mathrm{~K} / \mathrm{W}$. Figure 8 shows the importance of thermal resistance. In summary, the on-resistance is also determined by the speed of the heat removal. With more effective heat transfer a $20 \mathrm{~A}$ device may be able to handle 60-100 A or more as Cryo-MOS.

Cryo-MOS Reverse Recovery Time: One great advantage of the Cryo-MOS is the considerable reduction in the reverse recovery time as well as the reverse recovery charge by the cryogenic cooling. [3, $8,9]$.

Breakdown Voltage: A disadvantage of the Cryo-MOS is the fact that its breakdown voltage decreases by about $20 \%$ from the room temperature value if cooled down to $77 \mathrm{~K}$. Hammerton pointed out that the "avalanche obvershoot poses a hazard for MOSFETs" at low temperatures [17].

\section{THE IGBT: INSULATED GATE BIPOLAR TRANSISTOR}

At the present time the IGBT is the preferred device for multi-kilowatt power electronics in the 300-1000 $V$ range because room temperature operated MOSFETs have too high an on-resistance. Its equivalent circuit (Courtesy IRC Data Book) is given in Figure 15. A commutating diode must be added. At the left side is a MOSFET and its parasitic npn bipolar transistor. In order to obtain an IGBT one has to add (1) a junction FET, (2) a bipolar pnp transistor (BIT) and (3) a diode for inductive switching: Three additional components, with the key component being the pnp BIT! The latter brings back all the problems related with minority carrier storage, etc. In the case of the MOSFET one can say that its parasitic npn BIT becomes ineffective at low temperatures because of the considerable decrease of its current gain. But its collector-base diode acts as a commutating diode. Applying the basic engineering concept that simplicity provides better performance, one can state that the MOSFET is a better device than the IGBT if its drawback, high on-resistance at high voltages, is removed. This happens by cryo-cooling MOSFETs as has been shown by the measurements of Section 1: A new device is here: The Cryo-MOS. It contains basically 3 components versus 6 for the corresponding IGBT. In the following the key characteristics of a single die MOSFET (APT10050JN, $0.5 \Omega, 20.5 \mathrm{~A}, 0.24 \mathrm{~K} / \mathrm{W}$ ) 


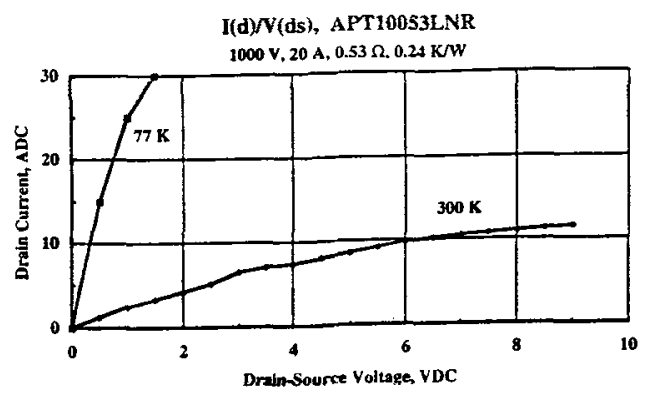

Figure 7

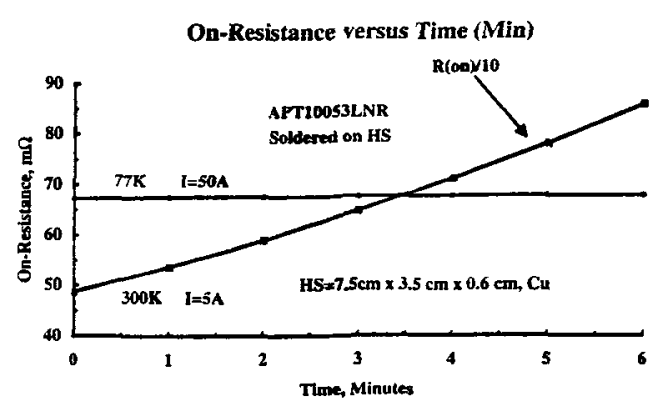

Figure 9

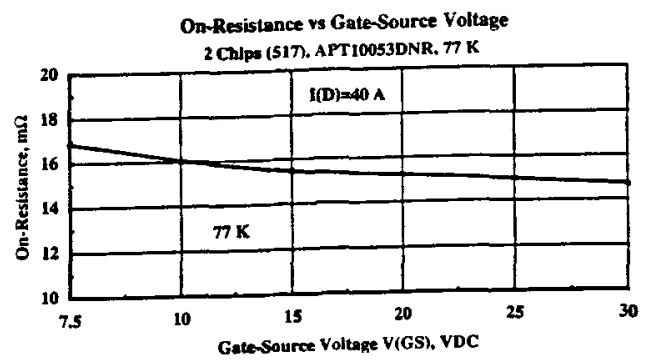

Figure 11

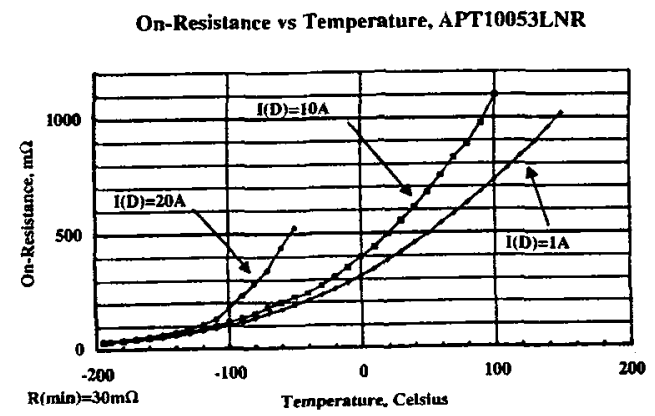

Figure 13

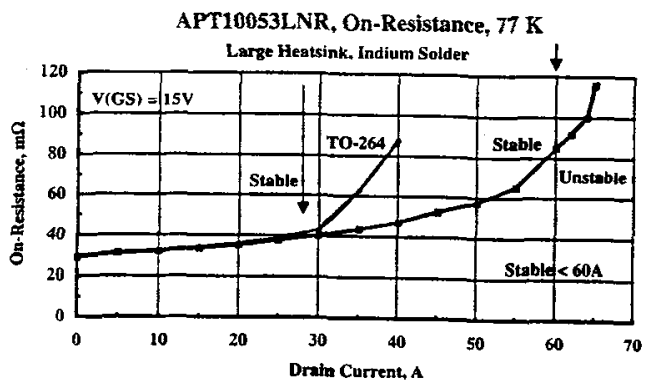

Figure 8

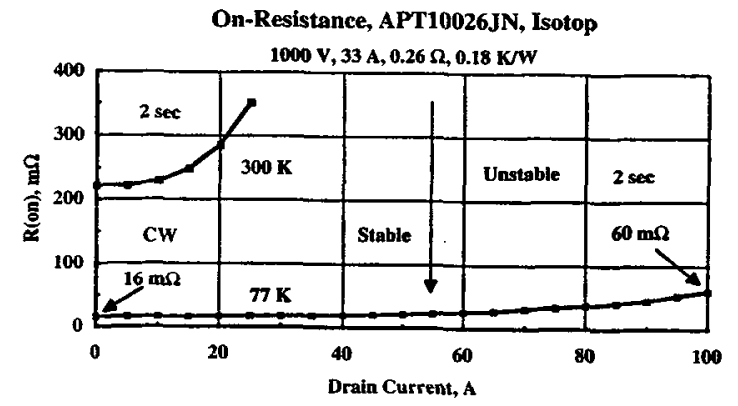

Figure 10

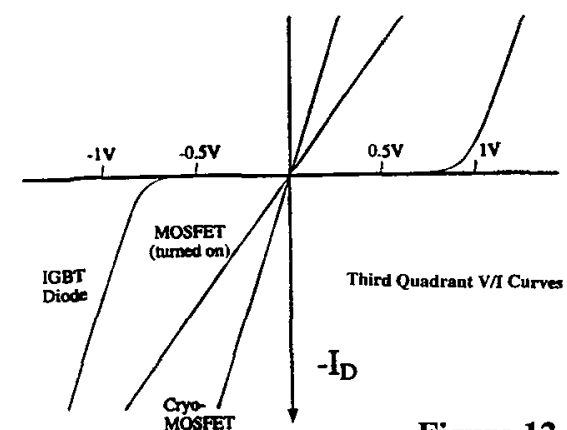

Figure 12

On-Resistance vs Temperature, APT10053LNR

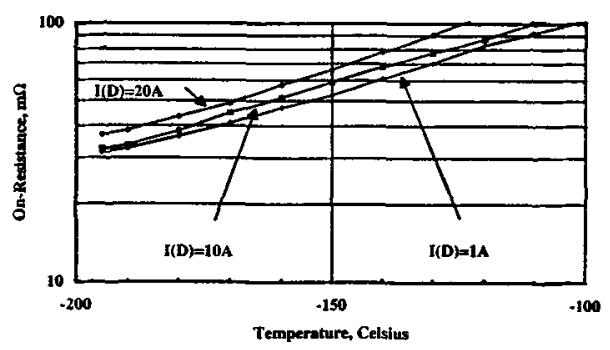

Figure 14 
Table 1

\section{Cryo-MOSFET versus IGBT: \\ Resistive Switching Losses}

\begin{tabular}{|c|c|c|}
\hline MG200Q2YS11 & MG300Q2YS40 & APT10026JN \\
\hline Low Saturation Voltage & High-Speed & \\
\hline $\begin{array}{l}1200 \mathrm{~V}, 200 \mathrm{~A} \\
\mathrm{~V}(\text { CEsat }): 2.2 \mathrm{~V}<2.7 \mathrm{~V}\end{array}$ & $\begin{array}{l}1200 \mathrm{~V}, 300 \mathrm{~A} \\
3.0 \mathrm{~V}<4.0 \mathrm{~V}\end{array}$ & $\begin{array}{l}1000 \mathrm{~V}, 40 \mathrm{~A} \\
\mathrm{~T}=77 \mathrm{~K}: 0.7 \mathrm{~V}\end{array}$ \\
\hline R(Gate): $\quad 4.7 \Omega$ & $2.7 \Omega$ & $0.6 \Omega$ \\
\hline \multicolumn{3}{|l|}{ Switching Times: } \\
\hline Rise Time: $0.3 \mu \mathrm{s}<0.6 \mu \mathrm{s}$ & $0.3 \mu \mathrm{s}<0.6 \mu \mathrm{s}$ & $19 \mathrm{~ns}<40 \mathrm{~ns}$ \\
\hline Fall Time: $0.6 \mu \mathrm{s}<1.0 \mu \mathrm{s}$ & $0.2 \mu s<0.5 \mu s$ & $14 \mathrm{~ns}<30 \mathrm{~ns}$ \\
\hline $900 \mathrm{~ns}<1600 \mathrm{~ns}$ & $500 \mathrm{~ns}<1100 \mathrm{~ns}$ & $33 \mathrm{~ns}<70 \mathrm{~ns}$ \\
\hline
\end{tabular}

Cryo-MOSFET versus IGBT Improvement Factor F :

$\begin{array}{ll}F=900 / 33=27 & F=500 / 33=15.0 \\ F=1600 / 70=23 & F=1100 / 70=15.7\end{array}$
IGBT

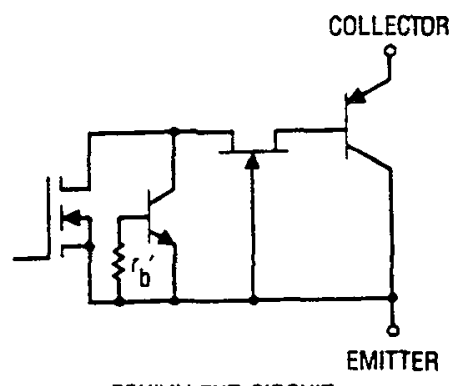

EQUIVALENT CIRCUIT

Figure 15

and a single die n-channel IGBT (APT90GF100JN, $90 \mathrm{~A}, 50 \mathrm{~A}$ at $\mathrm{T}_{\mathrm{C}}=90^{\circ} \mathrm{C}, 0.3 \mathrm{~K} / \mathrm{W}$ ) are compared. Both are rated $1000 \mathrm{~V}$, have the same die size (APT-107, APT207) and come in the ISOTOP package.

The Question of Current Density: In the past the "best" semiconductor power device was considered to be the one with the highest current density in $\mathrm{A} / \mathrm{cm}^{2}$. But high current density means high power density and high thermal resistance. Both are undesirable in high power electronics because they require large heatsinks and make miniaturization impossible. Since "silicon is cheap" one should look into the possibility of trading kilogram heatsinks for milligram silicon chips by paralleling. But due to the on-state threshold voltage (Figure 1) of IGBTs paralleling cannot be done with these devices. This may serve as introduction to the following discussion.

The chip area of the devices to be compared is $A=9.86 \mathrm{~mm} \times 14.95 \mathrm{~mm}=147.4 \mathrm{~mm}^{2}=\left(0.388^{\prime \prime} \mathrm{x}\right.$ $0.588^{\prime \prime}$. The current densities are then $13.9 \mathrm{~A} / \mathrm{cm}^{2}$ (MOSFET) and $61 \mathrm{~A} / \mathrm{cm}^{2}$ (IGBT), but only $33.9 \mathrm{~A} / \mathrm{cm}^{2}$ at $90^{\circ} \mathrm{C}$ case temperature. In all switchmode circuits with inductive loads commutating diodes are required. This diode is built-into the MOSFET from the collector-base junction of the npn transistor in Figure 15. In the case of the IGBT an external commutating diode has to be added, so the current densities of the IGBT must be divided by 2 assuming an equal diode chip size: The resulting die current density of $17 \mathrm{~A} / \mathrm{cm}^{2}$ (IGBT + diode) is then not much higher than the one for the MOSFET $\left(\sim 14 \mathrm{~A} / \mathrm{cm}^{2}\right)$. This comparison is even better for the MOSFET if one takes into account that it can carry in the cryocooled condition much higher currents than specified for $300 \mathrm{~K}$ (see Figures 2-10).

On-State Voltage: The IGBT (APT90GF100JN) on-state voltage is given in the data sheet for a current of $50 \mathrm{~A}\left(90^{\circ} \mathrm{C}\right.$ case temperature) as $2.6 \mathrm{~V}$ (typical) and $4 \mathrm{~V}$ (max). This corresponds to a conduction loss of $130 \mathrm{~W}<200 \mathrm{~W}$. If one uses two Cryo-MOS (at $77 \mathrm{~K}$ ) devices with each rated $25 \mathrm{~A}$ and an onresistance of $40 \mathrm{~m} \Omega$ each according to Figure 8 the on-state voltage would be $1.0 \mathrm{~V}$ and the power dissipation $50 \mathrm{~W}$. The silicon area is the same in both cases. The conduction loss is then a factor of 2.6 to 4 times lower for the Cryo-MOS than for the IGBT. By paralleling more Cryo-MOS devices one can increase the improvement factor to any desired number. With 4 times more Cryo-MOS chips the conduction loss would only be $10 \mathrm{~W}$ with a reduced on-resistance of $32 \mathrm{~m} \Omega$ for $6.25 \mathrm{~A}$ per device (Figure 8). The power dissipation due to conduction loss is then 13 to 20 times lower in the case of the CryoMOS. Liquid nitrogen cooling efficiency is about $1 \mathrm{~W} / 8 \mathrm{~W}$. Paralleling IGBTs is ineffective due to its onstate threshold voltage of $1 \mathrm{~V}$ to $1.5 \mathrm{~V}$.

Switching Times: Switching losses constitute the bulk of the circuit losses at higher frequencies. They depend to a large extent on the switching times of the devices. In this regard the Cryo-MOS has a distinct advantage if compared with the IGBT. The MOSFET is inherently the fastest power switching device. In addition it is not hampered by the so-called IGBT "tail-time" of its "tail-current". Table 1 presents a 
comparison of the switching times of 2 IGBTs and one MOSFET. They show that the latter is an order of magnitude faster than the IGBTs. MOSFETs have been used as RF amplifiers in the 1-100 MHz domain. Cooling also increases the switching speed [15].

Cost: Paralleling MOSFETs is, of course, also a cost problem. Up to the present time high-voltage (1000 V) MOSFETs have not been used in large quantities because of the available IGBTs. But if the Cryo-Power concept is successful then the demand for MOSFETs would drastically increase and the cost will come down. Paralleling MOSFETs basically means replacing large kilogram heatsinks by small milligram silicon dies.

\section{THE CRYO-IGBT?}

Can the IGBT be cryo-cooled? Rosenbauer and Lorenzen have shown that so-called non-punch-through (NPT) IGBTs can operate over the temperature range from $5 \mathrm{~K}$ (!) to $400 \mathrm{~K}$. They used them for protection of SMES (=Superconducting magnetic energy storage) coils [11]. Various papers have been published investigating the low-temperature behavior of IGBTs. The key problem is that the on-state voltage does not improve much with cooling. But the fall time decreases at low temperatures $[12,13]$.

\section{SUMMARY and CONCLUSIONS}

The Cryo-MOS could become a strong competitor to the IGBT in certain high-power applications. It should permit a drastic size, weight and cost reduction in some suitable power electronics circuits. Micro power-circuits are made possible by Cryo-MOS!

\section{ACKNOWLEDGMENTS}

The author is grateful to the management of ASC for the support of this work and the permission to publish it. Special thanks are due to Dr. R. Gran and Dr. A. Malozemoff.

\section{REFERENCES}

[1] Kirschman, R.K., Low-Temperature Electronics, (IEEE Press, 1986)

[2] Blanchard, R, Severns R., "Designing switched-mode power converters for very low temperature operation", Proceedings of Powercon 10, 1983. D2, 1-11.

[3] Mueller, O., Cryogenics, Vol. 29, (October 1989), 1006-1014.

[4] Schempp, E. Russo, C., "Applications of high-temperature superconducting coils as inductors in switching power supplies". Applied Superconductivity Conference, Chicago, August 23-28, 1992.

[5] Mueller, O. Herd, K.G., "Ultra-high efficiency power conversion using cryogenic MOSFETs and HTS superconductors." IEEE PESC-93 Record, 772-778.

[6] Dierberger, K., "Understanding the differences between standard MOSFETs and avalanche rated MOSFETs." PCIM Conference Proceedings, 9/1994.

[7] Hands, B.A., Cryogenic Engineering, (Academic Press, 1986).

[8] Vogler, T., Schröder, D., "A new and accurate circuit-modelling approach for the power diode." IEEE PESC-92 Record, 870-876.

[9] Singh, R., Baliga, B.J., Solid-State Electronics, (1994, Vol. 37, No.11), 1833-1839. (Diode)

[10] Singh, R. Baliga, B.J. Solid-State Electronics, (Vol. 36, No.8, 1993), 1203-1211. (MOSFET)

[11] Rosenbauer, F., Lorenzen, H.W., "Behavior of IGBT modules in the temperature range from 5K to $300 \mathrm{~K}$ ", Cryogenic Engineering Conference, Columbus, OH, July 1995, TU-PE2b-1.

[12] Godbold, C.V. Hudgins, J.L. Braun, C. Portnoy, W.M. "Temperature variation effects in MCTs, IGBTs, and BMFETs". IEEE PESC-93 Record, 93-98.

[13] Singh, R., Baliga, B.J., "Cryogenic operation of asymmetric n-channel IGBTs". Proc. 1992 Int. Symposium on Power Semiconductor Devices \& ICs, Tokyo, 188-193, and: Solid-State Electronics, Vol. 38, No. 3, 561-566.

[14] Singh, R., Baliga, B.J., "Cryogenic operation of power bipolar transistors", Proc. 6th International Symposium on Power Semioconductor Devices \& ICs. Paper 6.5, Davos, Switzerland, June 1994, 243-248.

[15] Kärner, J.F. Lorenzen, H.W. Rehm, W. "Semiconductors at low temperature". EPE Firence 1991.

[16] Mueller, O. Cryogenics, Vol. 30, Dec. 1990, 1090-1100.

[17] Hammerton, C.J., PCIM, January 1996, 52-57. 